\title{
A framework for understanding the characteristics of complexity in biology
}

\author{
Joseph Dauer ${ }^{*}$ and Jenny Dauer
}

\begin{abstract}
Understanding the functioning of natural systems is not easy, although there is general agreement that understanding complex systems is an important goal for science education. Defining what makes a natural system complex will assist in identifying gaps in research on student reasoning about systems. The goal of this commentary is to propose a framework that explicitly defines the ways in which biological systems are complex and to discuss the potential relevance of these complexity dimensions to conducting research on student reasoning about complexity in biology classrooms. We use an engineering framework for dimensions of complexity and discuss how this framework may also be applied to biological systems, using gene expression as an example. We group dimensions of this framework into components, functional relationships among components, processes, manifestations, and interpretations within biological systems. We explain four steps that discipline-based education researchers can use to apply these dimensions to explore student reasoning about complex biological systems.
\end{abstract}

Keywords: Biological systems, Complexity, Systems thinking, Undergraduate, Post-secondary

\section{Background}

For many science educators, the passion for our work stems from a deep sense of awe for the complexity of natural systems that we have come to recognize as beautiful. We also share a common goal to help students recognize, appreciate, and understand the complexities of natural phenomena. In particular, the intricacies of biological systems are important for students to understand for medical, environmental, and social health. Understanding how biological complexity is manifest at different levels of organization (molecules to ecosystems) is a major challenge for advancing twenty-first-century biology (National Research Council (NRC) 2009) and for preparing undergraduate students to address difficult issues that our society faces (American Association for the Advancement of Science (AAAS) 2011). This same goal is expressed in different ways throughout primary and secondary standards in the USA and post-secondary education, both generally in terms of sequences of increasing sophistication across grade bands and specifically in terms of concepts that students should master (AAAS 2011; NRC 2012).

\footnotetext{
* Correspondence: joseph.dauer@unl.edu

School of Natural Resources, University of Nebraska-Lincoln, 3310 Holdrege Street, Lincoln, NE 68583-0995, USA
}

Despite general agreement about the importance of understanding complexity, the meaning of "complexity" is not often defined. For example, NRC's "A Framework for K-12 Science Education" (2012) and the "Next Generation Science Standards" (NGSS Lead States 2013) in the USA promote scale and systems and systems modeling; however, the use of the word "complexity" throughout the documents includes as follow: "complex food molecules [sugars]," that "organisms are complex," and that ecosystems are "complex, interactive systems." The NRC framework does not specify what characteristics make molecules, organisms, or ecosystems complex.

A system has been described as complex (Jacobson 2001; Johnson 2009) if it exhibits particular characteristics including the following:

- Having many interacting agents

- Being affected by agents' behaviors (i.e., positive and negative feedback) that can be modified based on history

- Being open

- Having emergent properties that arise without a central control

- Showing patterns that arise both ordered and disordered 
Some of these characteristics are present in the way that complex biological systems are described in "Vision and Change in Undergraduate Biology Education: A Call to Action" (AAAS 2011), either explicitly or implicitly in the text. However, when thinking about biology instruction, a problem arises-complexity is not a singular idea, but rather has many characteristics. If a biology instructor wanted to make complexity a centerpiece of his or her curriculum, what is the best way to help students recognize, explain, and grapple with the characteristics of complexity in a way that is coherent and generalizable across levels of organization and different contexts? The goal of this commentary is to present a framework for a language of complexity that may aid instructors in this endeavor, as well as education researchers who seek to understand student learning about complexity.

\section{Explicitly addressing complexity in classrooms: the need for a complexity framework}

The characteristics of complex systems listed above are based on observations. The list, with the exception of feedback on behavior, does not reveal mechanistic or causal relationships that give rise to the observed phenomenon. We think that when learning about complex systems, students will benefit from a more concrete connection between mechanistic relationships and the resulting phenomenon with complex characteristics (Doyle et al. 2008; Hmelo et al. 2000; Jacobson \& Wilensky 2006; Wilensky \& Resnick 1999). For example, diffusion is the result of millions of molecules moving independently, yet students associate the term diffusion more with the phenomenon of moving from high concentration to low concentration than the causal mechanism of molecular kinetics (Garvin-Doxas \& Klymkowsky 2008). Focusing on mechanisms will mean extra footwork for an instructor to discuss both abstract system behaviors like movement of molecules and concrete examples like diffusion in lungs during gas exchange in a way that is explicitly linked (Goldstone \& Son 2005; Levy \& Wilensky 2008). But, revealing generalizable mechanisms can be a powerful way for students to make sense of systems, specifically explaining complexity at multiple biological scales and how this complexity impacts processes across these scales (Jacobson \& Wilensky 2006; Verhoeff et al. 2008).

There is a struggle inherent to introducing students to new concepts and portraying the depth of complexity that we hope to have them achieve by the time they have advanced in their learning. There is a danger of being too complex and losing students in cognitive overload (Reber \& Kotovsky 1997; Schnotz \& Kürschner 2007), but there is also a danger in being too simple in a way that promotes misconceptions (Feltovich et al. 2004) and can promote memorization instead of understanding
(Jiménez-Aleixandre et al. 2000). Students' misconceptions frequently arise from reductive biases (Spiro et al. 1988), which are tendencies to reduce important aspects of complexity. For example, medical students have been shown to misunderstand the impact of cardiac output on venous pressure because they treat a continuous process such as blood flow as a more simple discrete process (Feltovich et al. 1994). In cognitive flexibility theory, conditions that help students acquire knowledge while preventing reductive biases will allow students to master complexity and transfer this knowledge across contexts (Spiro et al. 1988). The conditions to promote mastery of complexity include avoiding oversimplification, providing multiple representations, increasing connectedness of concepts and skills, and offering explicit guidance on managing complexity (Hmelo-Silver et al. 2007; Jacobson \& Wilensky 2006; Spiro et al. 1988).

Chi (2005) provided an explanation about why some misconceptions about systems are so robust and supported the idea of instruction that explicitly addresses characteristics of complexity. She compared students' conceptual thinking about two processes: the flow of blood in human circulatory systems versus diffusion of dye in water. The flow of blood is an example of a direct process because the aggregate components of the heart (the structure of the chambers and valves) are directly causing the global pattern of blood direction and speed. Diffusion is an example of an emergent process because the mechanism is explained by the collective interaction of the dye and water molecules rather than any single or aggregate components. She observed that students' misconceptions of emergent processes are robust because they misinterpret emergent processes as a direct process. For example, students might explain diffusion as a series of sequential steps where first the oxygen "comes in" and then the carbon dioxide would "go out," rather than simultaneous movement of a collection of molecules (Chi 2005). Overcoming this misconception requires students to know about emergent processes in order to overcome their predisposition to conceive of all processes as direct. This conceptual change in systems thinking is difficult to achieve and may require students to first become aware of ontological categories such as "direct" and "emergent," and then shift their conceptions across categories (Chi, 2005). Therefore, students' lack of awareness of these categories may promote reductive biases. If generalizable explanations of processes are taught explicitly, they may help students recognize and understand a variety of systems characteristics in multiple contexts.

Instructors need additional resources to help them navigate a balance between being too complex and being over simplistic. Instructors also need resources to address generalized characteristics of complex systems in 
classrooms. We agree with Jacobson and Wilensky (2006) and Chi (2005) that providing instructors with explicit language to define what makes a system "complex" will help teachers be more adept in integrating specific aspects of complexity in their teaching and to determine when to include or exclude or draw connections between concepts. We propose a framework below to address this need, which represents generalizable dimensions of complexity that provide the ontological basis for complex systems.

\section{Adapting an engineering framework for biological complexity}

Our approach builds on the work of Feltovich and colleagues (Feltovich et al. 2001; Feltovich et al. 2004, 1994) who have identified eleven dimensions of complexity in engineered systems. Speaking from their expertise in cognition, they suggest that these eleven dimensions of complexity make designing systems (in their case, intelligent design systems) very difficult. They suggest that the reductive biases of learners in general, and cognitive engineers specifically, result in oversimplification and eventually poor performance and misconceptions.

Biological systems evolved through eons of time and are not constructed and therefore not exactly analogous to engineered systems (Modell et al. 2015). Despite the difference between engineered and biological systems, we propose that these eleven characteristics are a useful framework for approaching research on student learning about biological systems and aid biology educators and researchers to move beyond the phenomenological descriptions of systems. By doing so, we are also proposing that there are a relatively small number of definable characteristics that make living systems complex.

In order to more clearly apply these dimensions to biology, we grouped Feltovich et al.'s dimensions into those that deal with the components of the system, the functional relationships (i.e., mathematical relationships) among components, the processes by which components interact, the manifestation of those relationships and processes, and the interpretation of the system or how a given biological system may viewed differently by different audiences both in terms of functionality and representation. We changed the name of one original dimension from "mechanism/organicism" to "deterministic/ emergent" to better align with familiar terminology in biology. We eliminated another dimension ("surface/ deep") because we felt this dimension was encompassed by all of the other dimensions. The 10 dimensions are described in Table 1 with an eye toward the hypothesis that students may be susceptible to reductive biases in one or more dimensions.

Previous science education research have proposed ways to investigate student understanding of complex systems. One example is the structures-behaviorfunction (SBF) framework that has been used to both support and research students' systems thinking (Bray-Speth et al. 2014; Dauer et al. 2013; Hmelo-Silver et al. 2007;

Table 1 Dimensions of complexity (right column), taken and adapted from Feltovich et al. (2004), organized into components, functional relationships, etc. The middle column represents the potential reductive tendencies that affect learners' reasoning about complex biological systems (Spiro et al. 1988)

\begin{tabular}{|c|c|c|}
\hline & Reductive tendencies & Systems thinking \\
\hline Components & $\begin{array}{l}\text { Homogeneous: components are similar and } \\
\text { perform similarly. }\end{array}$ & $\begin{array}{l}\text { Heterogeneous: components are diverse and have } \\
\text { diverse reponses. }\end{array}$ \\
\hline \multirow[t]{3}{*}{ Functional relationships } & $\begin{array}{l}\text { Linear: changes and interventions will have } \\
\text { incremental impact. }\end{array}$ & $\begin{array}{l}\text { Non-Linear: relationships between the variables are } \\
\text { nonproportional. }\end{array}$ \\
\hline & Discrete: processes have discernable steps. & Continuous: Processes proceed in unbreakable continua. \\
\hline & Separable: processes occur in isolation. & $\begin{array}{l}\text { Interactive: Processes have strong interactions and are } \\
\text { interdependent. }\end{array}$ \\
\hline \multirow{3}{*}{ Processes } & Sequential: process have steps that occur in serial. & Simultaneous: multiple processes occur at the same time. \\
\hline & $\begin{array}{l}\text { Static: multiple processes within systems are unchanging } \\
\text { and can be captured in a single "snapshot". }\end{array}$ & $\begin{array}{l}\text { Dynamic: critical characteristics are captured only by changes } \\
\text { from frame to frame, possessing vector-like characteristics. }\end{array}$ \\
\hline & $\begin{array}{l}\text { Deterministic: products are a result of simple cause } \\
\text { and effect. }\end{array}$ & $\begin{array}{l}\text { Emergent: results are products of systemwide, organic } \\
\text { functions, requiring understanding the entire system to } \\
\text { understand the parts well. }\end{array}$ \\
\hline \multirow[t]{2}{*}{ Manifestations } & Universal: products will be the same in multiple contexts. & $\begin{array}{l}\text { Conditional: application of principles do not hold across } \\
\text { different situations, requiring sensitivity to context. }\end{array}$ \\
\hline & $\begin{array}{l}\text { Regular: phenomena exhibit symmetry and repeatable } \\
\text { patterns. }\end{array}$ & $\begin{array}{l}\text { Irregular: phenomena exhibit asymmetry and absence of } \\
\text { consistent patterns. }\end{array}$ \\
\hline Interpretation & $\begin{array}{l}\text { Single representation: a single viewpoint captures } \\
\text { multiple processes. }\end{array}$ & $\begin{array}{l}\text { Multiple Representations: elements in a situation afford many } \\
\text { interpretations, functional uses, categorizations and so on, so that } \\
\text { multiple schemas, analogies, models or case precedents are } \\
\text { needed to capture and convey the meaning of the situation. }\end{array}$ \\
\hline
\end{tabular}


Liu \& Hmelo-Silver 2009; Vattam et al. 2011). Like the framework we propose in this article, SBF was first utilized in engineered systems (Goel \& Stroulia, 1996) then adapted by Hmelo-Silver and colleagues in biological systems (Hmelo-Silver et al. 2007; Hmelo-Silver \& Pfeffer 2004; Jordan et al. 2008). Another commonality between the SBF model and the framework we propose is that components in our framework mirrors "structures" in SBF representations and is a critical piece for teaching students about complex systems. As Hmelo-Silver et al. (2007) point out, it is a critical first step for learners to be aware of the components in order to describe the operation of the system. However, our proposed framework for complexity in biological systems differs from the SBF framework in important ways. "Behaviors" and "functions" do not map exactly onto our framework. Our framework describes the ontological level of behavior, so processes in our framework explain behaviors. For example, air moving in and out of the lungs is a behavior facilitated by the lungs and diaphragm (structures/components). The process of air moving in and out of the lungs is a continuous, interactive, simultaneous, and dynamic set of processes. SBF representations, like student-created models, are limiting in that the nature of some processes cannot easily be represented in the models frequently used to elicit learners' mental models of the systems (Dauer et al. 2013; Hmelo-Silver et al. 2007). For example, representing the diffusion of oxygen and carbon dioxide across a capillary wall in a lung as a simultaneous (not sequential) process is challenging in a static drawing unless the learner specifically reports this process as simultaneous. Similarly, the function, or purpose of the system, e.g., to facilitate gas exchange, is not captured in our framework, except somewhat in the interpretation dimension. Instead, in our framework, the manifestation dimensions describe how the combination of processes is manifest in the system and the nature of those manifestations. Again, SBF representations have some limitations in that the nature of some manifestations may be challenging to represent in a static drawing unless specifically noted.

The goal of this commentary is to present a framework for complexity dimensions and to discuss the potential relevance of these complexity dimensions to teaching and to conducting research on student reasoning about complexity in biology classrooms. This framework of complexity dimensions can aid researchers in using a more specific language around complexity and inspire new potential research questions around student learning. At present, there are significant gaps in research about undergraduate student reasoning about complexity, and our understanding of student reasoning is crucial for teaching biological systems. We present a sort of prescription for how a biology education researcher may use the dimensions of complexity, using gene expression as an example, to highlight how we have found these dimensions to be useful in organizing our own thinking about potential research questions.

\section{Discussion}

Determine how the biological concept is complex

We find it useful to first examine a single biological concept to determine how the dimensions of complexity are reflected in the characteristics of the concept. When considering the concept of gene expression, we can separately consider components, functional relationships, processes, manifestations, and interpretation (Table 1) to make explicit the ontological dimensions of complexity. The components of the system include DNA and RNA sequences, ribosomes, and proteins. The functional relationships are the rates and frequencies of biochemical reactions that happen at an atomic, molecular, cellular, and organismal level and contribute to a phenotype. The processes in gene expression include the following: transcription, translation, gene regulation by transcription factors, and interactions with the environment. The manifestation of gene expression is the phenotype of an organism, either directly if one gene-one trait or indirectly through protein interactions. The interpretation might include multiple representations (or models) of gene expression that highlight subcellular, cellular, organismal, or population levels of biological organization to be used for various purposes. For example, a physician or scientist may view the gene expression system with a different lens depending on if the context is medical, ecological, evolutionary, or hereditary.

Next, we can consider how gene expression might be complex and hypothesize about potential reductive tendencies of our students when reasoning about this complexity. The components may be "heterogeneous" because mutations in DNA nucleotide sequences occur frequently and may or may not be corrected, become fixed in the population, or be expressed at all. The functional relationships may be "non-linear" because transcription factors may have a pleiotropic, cascading effect (Hadorn 1961). The processes in gene expression may be "interactive" because transcription occurs only when regulatory factors are readily available from previous transcription and translation processes (Latchman 2010). The manifestation of the process of gene expression can be "conditional" because of two different mechanisms: (1) gene expression in different body organs may be due to differential gene regulation or (2) gene expression may be influenced by epigenetics due to environmental factors (Ansel et al. 2008; Shah \& Sukumar 2010).

When a biological concept is broken down into components, processes, manifestations, and so on, it will clarify and organize why gene expression may be considered complex. Explicitly identifying processes and 
manifestations aid students who are prone to focus on just the components of a system (Batzri et al. 2015; Hmelo-Silver et al. 2007), in developing systems thinking or the ability to consider many of the dimensions of a system simultaneously. Breaking down concepts this way may aid instructors in being aware of when and how to break down content into simpler pieces without oversimplifying in a way that may hinder students from a deeper level of understanding as they progress in their learning (Spiro et al. 1988). A framework of generalizable dimensions of complexity may give instructors ideas for how to illustrate complexity more accurately or to include "exceptions to the rule" that play an important role in the fabric of living systems. There are volumes of literature on students' lack of general knowledge about genes, alleles, chromosomes, and proteins (Couch et al. 2015; Garvin-Doxas \& Klymkowsky 2008; Smith et al. 2008; Tsui \& Treagust 2010). Focusing on one particular dimension within a biology concept, such as how the manifestations of gene expression are "conditional" or "universal," may direct and simplify how we approach research questions about how students reason about gene expression. For the remainder of our example, we chose to consider how teachers could instruct about conditional manifestations within the concept of gene expression due either to gene regulation or epigenetics.

\section{Investigate what is known about how students reason about this dimension}

Naturally, the best place to begin a research question is by examining primary literature about student learning within this dimension. Using the complexity framework to research student learning about biology is novel, as suggested by the lack of previous literature at this detailed level of analysis. We have found an uneven amount of research conducted on some dimensions compared to others. For example, there is literature on student reasoning about emergent manifestations (Hmelo-Silver \& Pfeffer 2004; Jacobson 2001; Levy \& Wilensky 2008; Wilensky \& Resnick 1999) but no research, that we could find, about student learning of conditional manifestations. Our proposed framework of complexity in biology may be useful in highlighting opportunities for new research focusing on one particular dimension of complexity. However, there is a lack of overall guidance in the literature on the relative importance, relevance, and learning difficulty of any particular dimension, so some aspects of the framework may prove to be more fruitful than others.

As we investigated literature, we found articles suggesting teaching strategies related to gene regulation and epigenetics (for example, Colón-Berlingeri 2010; DritsEsser et al. 2014; Heyduck \& Harms 2015), but not directly related to reasoning about conditional manifestations related to gene expression. Some aspects of gene regulation are less complex and easier for students to understand according to the literature. For example, students' conceptions about which cells in an organism possess genes for a given trait can be remedied during instruction (Makarevitch et al. 2015). (All cells except red blood cells and cornified cells in your skin, hair, and nails possess a copy of each gene in the genome, although there are copy number variations within different cells of an organism (Redon et al., 2006).) However, other aspects of gene regulation and epigenetics are more difficult for students to understand and relate to familiar concepts of the transcription and translation. For example, of advanced molecular biology students who understand the impact of transcription factors, $30 \%$ are unable to reason about methylation or the regulation of transcription factors by environmental cues (Couch et al. 2015). After our literature search, we gained little insight on student tendencies toward simplistic explanations of gene expression by ignoring differential gene regulation in organisms or epigenetics. Therefore, there exists an opportunity for research on how students learn about conditional manifestations in general and specifically related to gene expression.

\section{Look for reductive tendencies in student explanations}

The initial data to be collected about student reasoning about complexity dimensions in the context of biology may take multiple forms such as constructed models, short answer explanations, interviews, or multiple-choice questions. Constructed models (from question prompts targeting specific dimensions) may provide critical information about some dimensions, for example, heterogeneous components, simultaneous processes, or non-linear functional relationships (Bray-Speth et al. 2014; Dauer et al. 2013; Liu \& Hmelo-Silver 2009). For example, in a recent semester, introductory biology students at our university constructed conceptual models of gene regulation of expression and struggled to represent simultaneous events in the lac operon system (JT Dauer, unpublished data).

Students' written explanations or verbal explanations in an interview may be the most effective way to reveal the nuances of student reasoning about complexity, especially pertaining to the processes and manifestations present in the system. Interview questions that ask student to explain gene expression phenomena may reveal students' reductive tendencies or difficulty understanding gene regulation or epigenetics. Examples are as follows:

- Cells in the human body contain 46 chromosomes, making up approximately 20,000 different proteincoding genes. Where in the body does gene expression occur? Are all the coding regions active in every cell in our bodies? Why or why not? 
- In a multicellular organism, cells contain the same genes. However, these organisms generally have many different cell types with different morphology and physiology (e.g., neurons versus liver cells). How is this possible?

- Cells in the liver and the pancreas contain both the gene for the protein serum albumin that makes up blood plasma and the gene for protein amylase that helps digest starch. However, only the liver produces the protein serum albumin and only the pancreas produces amylase. Can you explain why? Can you explain how this happens?

- Identical twins have an identical set of genes. Do identical twins have the same gene expression? Can anything from an individual twin's life experiences influence what genes are producing proteins in their body? Why? How?

The result of this research would be a first-order approximation of student reasoning of the complexity dimension in a given context. Fully capturing students' mastery of complexity would require extensive research for the other nine dimensions plus interactions among dimensions, applied to multiple biology concepts-an overwhelming proposition. But small steps, like focusing on a single understudied dimension or applying what is known from well-studied dimensions to similar dimensions, can lead to generalizations that will advance our knowledge about how students know and learn complexity.

\section{Design an intervention to test if reductive tendencies can be overcome}

Continuing with our example of conditional manifestations in gene expression, the next step would be to design a set of instructional material and assessments or to refine existing materials based on results from observations of student thinking. The results of observations in step 3 should help inform learning objectives, support tools, and assessments. Instructional materials should be designed to support student explanations to include the complexity and nuance of regulation of gene expression and epigenetics. An instructor should be explicit in linking biological phenomena to the concept that the process and quantity of transcription and translation are conditional on the presence of transcription factors and environmental cues. Instructors may explicitly discuss with students how manifestations of process that occur at the atomic and cellular levels in a living organism may be conditional, emergent, or irregular and that gene expression is an example of a conditional manifestation.

There are many existing resources on regulation of gene expression and epigenetics (Billingsley \& Carlson 2010; Colón-Berlingeri 2010; Drits-Esser et al. 2014;
Militello 2013) that could be modified to provide an intervention to student learning grounded in how students learn this dimension of complexity. An example is Makarevitch et al. (2015) who have designed gene expression laboratory exercises related to abiotic stress effects on maize. Their curriculum for upper-level genetics classrooms allows students to propose hypotheses about how stress may affect the expression of different genes, then explore online repositories of gene expression data to test their hypotheses. This inquiry approach is carefully choreographed to allow student inquiry while maintaining a focus on the underlying biological content.

We also envision derivations of this approach that may further emphasize conditional manifestations or other dimensions of complexity in a simulated environment. Simulations provide an excellent opportunity for students to model, quantify, or visualize systems complexity. Learn.Genetics (http://learn.genetics.utah.edu) provides interactive visualizations of epigenetics. Several resources exist for designing or modifying simulations to improve visualizing complex systems. For example, Wilensky, colleagues, and other contributors (Jacobson \& Wilensky, 2006; Resnick \& Wilensky, 1998; Wilensky \& Resnick, 1999) have developed models using a multi-agent simulator called NetLogo, that allows users to simulate systems through simple rules governing the agents and the environment (the extensive reference list is available at: http:// ccl.northwestern.edu/netlogo/references.shtml). The Cell Collective (http://cellcollective.org), while focused currently on cellular scale systems, allows computational biologists and students to create models of biological systems with or without the underlying mathematical expression (Helikar et al., 2012, 2015). These software platforms may allow researchers to develop learning modules related to specific dimensions of complexity and test the efficacy of instructional materials related to these dimensions.

\section{Conclusions}

This essay seeks to promote greater discussion around the idea of what makes biological systems complex and how we can improve students' learning about complexity. While we, as a science community, often use the term complexity to describe biological systems, we suspect most of us have not considered what we really mean by complexity. While the term "complexity" is widely and ambiguously used in education, there are a finite number of ways why a biological system is complex. Feltovich et al. (2004) provided a framework to disentangle systems complexity into a small number of dimensions. We do not think Feltovich et al. intended their framework to necessarily apply to a biology classroom; however, we attempted to show how it can be used to guide research on how students learn complexity and 
ultimately guide instruction that assists students in learning about complex biological systems.

Obviously, instructors will always need to simplify concepts when they present new ideas to students. Without a clear definition of systems complexity, it is not easy for instructors to know how to simplify concepts or how to deliberately present additional complexity in instruction. Additionally, instructors may lack language that could be used to provide explicit instruction on generalizable concepts of complexity. The framework we propose may provide a roadmap of the ontology of complexity for both instructors and researchers as they explore a range of biological systems understanding from reductive tendencies to expert systems thinking.

\section{Acknowledgements}

We would like to thank J. Momsen, E. Offerdahl, E. Bray-Speth, T. Long, K. Montooth, T. Helikar, and numerous reviewers for their thoughtful comments and suggestions on the earlier versions of this manuscript.

\section{Authors' contributions}

The two authors of this paper equally shared responsibility for conceptua development and writing of this manuscript. Both authors read and approved the final manuscript

\section{Authors' information}

JTD is an Assistant Professor of Life Science Education and studies student learning in undergraduate biology courses. He studied plant ecology focused on population dynamics and seed dispersal for his MS and PhD in Ecology at Penn State University. JTD was a post-doctoral research at Michigan State University on student conceptual model construction in biology. In education, he has examined how conceptual modeling reflects students' changing understanding of biology concepts like the central dogma, homeostasis, and community interactions. His work is motivated by difficulties in students' conceptual and mathematical reasoning with complex biological systems. JMD is an Assistant Professor of Science Literacy in the School of Natural Resources, University of Nebraska-Lincoln. Her BS was in Secondary Education and Biology, MS in Ecology at Penn State University. JMD obtained a PhD in Forest Science from Oregon State University studying calcium cycling in forests. During her post-doctoral research at Michigan State University, she investigated secondary students' learning about matter and energy. JMD's current research interests include students systems thinking in biology and understanding postsecondary students' science-informed decision-making about socioscientific issues.

\section{Competing interests}

The authors declare that they have no competing interests.

Received: 1 April 2016 Accepted: 28 July 2016

Published online: 09 August 2016

\section{References}

AAAS. (2011). Vision and change in undergraduate biology education: a call to action.

Achieve, Inc. (2013). Next generation science standards. Washington, DC: Achieve, Inc. Retrieved from http://www.nextgenscience.org/next-generation-sciencestandards.

Ansel, J., Bottin, H., Rodriguez-Beltran, C., Damon, C., Nagarajan, M., Fehrmann, S., .. Yvert, G. (2008). Cell-to-cell stochastic variation in gene expression is a complex genetic trait. PLoS Genetics, 4(4), e1000049.

Batzri, O., Ben-Zvi Assaraf, O., Cohen, C., \& Orion, N. (2015). Understanding the Earth systems: expressions of dynamic and cyclic thinking among university students. Journal of Science Education and Technology, 24(6), 761-775.

Billingsley, J., \& Carlson, K. A. (2010). Epigenetic effects of diet on fruit fly lifespan: an investigation to teach epigenetics to biology students. The American Biology Teacher, 72(4), 231-234.
Bray-Speth, E., Shaw, N., Momsen, J., Reinagel, A., Le, P., Taqieddin, R., \& Long, T. (2014). Introductory biology students' conceptual models and explanations of the origin of variation. CBE-Life Sciences Education, 13(3), 529-539.

Chi, M. (2005). Commonsense conceptions of emergent processes: why some misconceptions are robust. The Journal of the Learning Sciences, 14(2), 161-199.

Colón-Berlingeri, M. (2010). Using an active-learning approach to teach epigenetics. The American Biology Teacher, 72(4), 221-222.

Couch, B. A., Wood, W. B., \& Knight, J. K. (2015). The molecular biology capstone assessment: a concept assessment for upper-division molecular biology students. CBE Life Sciences Education, 14(1), 1-11.

Dauer, J. T., Momsen, J. L., Speth, E. B., Makohon-Moore, S. C., \& Long, T. M. (2013). Analyzing change in students' gene-to-evolution models in college-level introductory biology. Journal of Research in Science Teaching, 50(6), 639-659.

Doyle, J., Radzicki, M., \& Trees, W. (2008). Measuring change in mental models of complex dynamic systems. In H. Qudrat-Ullah, J. M. Spector, \& P. I. Davidsen, Complex Decision Making (pp. 269-294). Berlin Heidelberg: Springer.

Drits-Esser, D., Malone, M., Barber, N., \& Stark, L. (2014). Beyond the central dogma: bringing epigenetics into the classroom. The American Biology Teacher, 76(6), 365-369.

Feltovich, P., Coulson, R. L., \& Spiro, R. J. (2001). Learners'(mis) understanding of important and difficult concepts: a challenge to smart machines in education. In K. Forbus \& P. J. Feltovich (Eds.), Smart machines in education: the coming revolution in educational technology (pp. 349-375). Menlo Park: AAAI/MIT Press.

Feltovich, P., Hoffman, R. R., Woods, D., \& Roesler, A. (2004). Keeping it too simple: how the reductive tendency affects cognitive engineering. IEEE Intelligent Systems, 19(3), 90-95.

Feltovich, P., Spire, R. J., Coulson, R. L., \& Adami, J. F. (1994). Conceptual understanding and stability, and knowledge shields for fending off conceptual change. Springfield: Southern Illinois University School of Medicine.

Garvin-Doxas, K., \& Klymkowsky, M. W. (2008). Understanding randomness and its impact on student learning: lessons learned from building the biology concept inventory (BCI). CBE-Life Sciences Education, 7(2), 227-233.

Goel, A., \& Stroulia, E. (1996). Functional device models and model-based diagnosis in adaptive design. Artificial Intelligence for Engineering, Design, Analysis and Manufacturing, 10(04), 355-370.

Goldstone, R. L., \& Son, J. Y. (2005). The transfer of scientific principles using concrete and idealized simulations. Journal of the Learning Sciences, 14(1), 69-110.

Hadorn, E. (1961). Developmental genetics \& lethal factors. London: Methuen and Co Ltd, John Wiley and Sons, Inc.

Helikar, T., Cutucache, C. E., Dahlquist, L. M., Herek, T. A., Larson, J. J., \& Rogers, J. A. (2015). Integrating interactive computational modeling in biology curricula. PLoS Computational Biology, 11(3), e1004131.

Helikar, T., Kowal, B., McClenathan, S., Bruckner, M., Rowley, T., Madrahimov, A., ... Rogers, J. A. (2012). The cell collective: toward an open and collaborative approach to systems biology. BMC Systems Biology, 6(1), 96.

Heyduck, B., \& Harms, U. (2015). An out-of-school practical exercise: an examination of different DNA methylation conditions using a restriction assay. Journal of Biological Education, 49(2), 179-189.

Hmelo, C. E., Holton, D. L., \& Kolodner, J. L. (2000). Designing to learn about complex systems. Journal of Learning Science, 9(3), 247-298.

Hmelo-Silver, C. E., Marathe, S., \& Liu, L. (2007). Fish swim, rocks sit, and lungs breathe: expert-novice understanding of complex systems. Journal of Learning Science, 16(3), 307-331.

Hmelo-Silver, C. E., \& Pfeffer, M. G. (2004). Comparing expert and novice understanding of a complex system from the perspective of structures, behaviors, and functions. Cognitive Science: A Multidisciplinary Journal, 28(1), 127-138.

Jacobson, M. (2001). Problem solving, cognition, and complex systems: differences between experts and novices. Complexity, 6(3), 41-49.

Jacobson, M., \& Wilensky, U. (2006). Complex systems in education: scientific and educational importance and implications for the learning sciences. Journal of the Learning Sciences, 15(1), 11-34.

Jiménez-Aleixandre, M. P., Bugallo Rodríguez, A., \& Duschl, R. A. (2000). “Doing the lesson" or "doing science": argument in high school genetics. Science Education, 84(6), 757-792. http://doi.org/10.1002/1098-237X(200011)84: 6<757::AID-SCE5>3.0.CO;2-F.

Johnson, N. (2009). Two's company, three is complexity. In Simply complexity: a clear guide to complexity theory (pp. 3-18). London: Oneworld Publications.

Jordan, R., Gray, S., Demeter, M., Liu, L., \& Hmelo-Silver, C. (2008). Adding behavior to thinking about structures \& function. American Biology Teacher, 70(6), 329-330. 
Latchman, D. S. (2010). Gene control. New York: Garland Science, Taylor and Francis Group, LLC.

Levy, S. T., \& Wilensky, U. (2008). Inventing a "mid level" to make ends meet: reasoning between the levels of complexity. Cognition and Instruction, 26(1), $1-47$.

Liu, L., \& Hmelo-Silver, C. E. (2009). Promoting complex systems learning through the use of conceptual representations in hypermedia. Journal of Research in Science Teaching, 46(9), 1023-1040.

Makarevitch, l., Frechette, C., \& Wiatros, N. (2015). Authentic research experience and "big data" analysis in the classroom: maize response to abiotic stress. CBE-Life Sciences Education, 14(3), 1-12.

Militello, K. T. (2013). Studying epigenetic DNA modifications in undergraduate laboratories using complementary bioinformatic and molecular approaches. Biochemistry and Molecular Biology Education, 41(5), 334-340.

Modell, H., Cliff, W., Michael, J., McFarland, J., Wenderoth, M. P., \& Wright, A. (2015). A physiologist's view of homeostasis. Advances in Physiology Education, 39(4), 259-266.

National Research Council. (2012). In S. R. Singer, N. R. Nielsen, \& H. A. Schweingruber (Eds.), Discipline-based education research: understanding and improving learning in undergraduate science and engineering. Washington, D.C: The National Academies Press.

NRC. (2009). A new biology for the 21st century. Washington, D.C.: National Academies Press.

Reber, P. J., \& Kotovsky, K. (1997). Implicit learning in problem solving: the role of working memory capacity. Journal of Experimental Psychology: General, 126(2), 178.

Redon, R., Ishikawa, S., Fitch, K. R., Feuk, L., Perry, G. H., Andrews, T. D., ... Hurles, M. E. (2006). Global variation in copy number in the human genome. Nature, 444(7118), 444-454.

Resnick, M., \& Wilensky, U. (1998). Diving into complexity: developing probabilistic decentralized thinking through role-playing activities. The Journal of the Learning Sciences, 7(2), 153-172.

Schnotz, W., \& Kürschner, C. (2007). A reconsideration of cognitive load theory. Educational Psychology Review, 19(4), 469-508.

Shah, N., \& Sukumar, S. (2010). The Hox genes and their roles in oncogenesis. Nature Reviews Cancer, 10(5), 361-371.

Smith, M. K., Wood, W. B., \& Knight, J. K. (2008). The genetics concept assessment: a new concept inventory for gauging student understanding of genetics. CBE - Life Sciences Education, 7, 422-430.

Spiro, R. J., Coulson, R. L., Feltovich, P., \& Anderson, D. K. (1988). Cognitive flexibility theory: advanced knowledge acquisition in ill-structured domains. In V. Patel (Ed.), Tenth annual conference of the cognitive science society proceedings (pp. 375-383). Hillsdale: Erlbaum. http://www.academia.edu/ download/30566058/24-710-Chapter22.pdf.

Tsui, C.-Y., \& Treagust, D. (2010). Evaluating secondary students' scientific reasoning in genetics using a two-tier diagnostic instrument. International Journal of Science Education, 32(8), 1073-1098.

Vattam, S. S., Goel, A. K., Rugaber, S., Hmelo-Silver, C. E., Jordan, R., Gray, S., \& Sinha, S. (2011). Understanding complex natural systems by articulating structure-behavior-function models. Journal of Educational Technology and Society, 14(1), 66-81.

Verhoeff, R. P., Waarlo, A. J., \& Boersma, K. T. (2008). Systems modelling and the development of coherent understanding of cell biology. International Journal of Science Education, 30(4), 543-568.

Wilensky, U., \& Resnick, M. (1999). Thinking in levels: a dynamic systems approach to making sense of the world. Journal of Science Education and Technology, 8(1), 3-19.

\section{Submit your manuscript to a SpringerOpen ${ }^{\mathcal{O}}$ journal and benefit from:}

- Convenient online submission

- Rigorous peer review

- Immediate publication on acceptance

- Open access: articles freely available online

- High visibility within the field

- Retaining the copyright to your article 